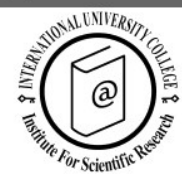

\title{
Andrews, H. (Ed.) (2014) Tourism and violence. Ashgate \\ Publishing limited. xvi+250pp. (figures, tables, bibliography, index), Price £58.50. ISBN: 978-1-4094-3640-9. (Hardback).
}

\author{
Reviewed by Juan M. Tello
}

Received: 30/07/2015

\begin{abstract}
${ }^{1}$ Economic and Business Research Institute, Universidad Michoacana de San Nicolás de Hidalgo, ININEE Building. Morelia, Michoacán, México; e-mail: juan.tello@me.com
\end{abstract}

(C) 2016 Varna University of Management. All rights reserved

Citation Andrews, H. (Ed.) (2014) Tourism and violence. Ashgate Publishing limited. xvi+250pp. (figures, tables, bibliography, index), Price £58.50. ISBN: 978-1-4094-3640-9. (Hardback). Reviewed by Juan M. Tello, European Journal of Tourism Research 12, pp. 228-229

Hazel Andrews at John Moores University in Liverpool, UK has written and edited a pioneering attempt to integrate violence into the tourism research. Using cases from a range of disciplinary approaches, this book is a fundamental work for understanding the role that violence plays in tourism. It is a work that shows the dark side of tourism and violence as part of the industry. The thirteen essays that make up the book illustrate the negative side of human behavior and the morbidity caused by violence as a tourist attraction.

Violence is a form of interaction between subjects manifested in behavior or in situations: either deliberately learned, intimidated, or threatened to physical, verbal, or psychological harm either to an individual or a community. Violence, being a form of interaction between subjects, occurs in tourism through political instability, terrorism, insecurity and crime.

This book intends to understand the role of violence in shaping products and tourism practices, in addition to addressing its understanding from a multidisciplinary approach with social, anthropological and ethnographic perspectives. In Chapter 2, drawing on a selection of ethnographic spaces of transit, Les Roberts sets out to explore the violence of "non places" (the disruption of the habitus place), and casts a closer critical reflection on the spatial anthropology of these landscapes as spaces of violence. These violent effects can be experienced as horrific and destructive, but they also allow for the cultivation of more positive feelings of dislocation.

In Chapter 3, Lozanski reflects on the violence that occurs in "other" places (those defined through racial, religious, and cultural differences from Western - centric norms, or Third World geographies). Lozanski argues that in developed countries, violence is not usually visible, while it is more visible in "other" places. When tourists are attacked in these "other" places, law enforcement is more efficient. Finally, it poses the contradictions between traveller's fantasies of, and aversions to, violence. 
Chapter 4 is a discussion of the ways in which violence towards women appears to be sanctioned in aspects of the everyday tourism practices. In particular, the author examines examples from two islands in the western Mediterranean, one from Menorca and one from Mallorca.

In Chapter 5, Louise Platt analyses Liverpool's case using ethnographic data. The author considers how the myths of the city of Liverpool can be linked to popular culture. Platt also explains that the city's re-branding in 2008 depended on the mythological greatness of Liverpool's past. The author shows that linguistic violence can be enabling when applied to the case of place image or myths of place.

Since the 1980's, battlefield tourism was reactivated in France, in particular through the emergence of tourism policies that place value on war heritage. In Chapter 6, Anne Hertzog demonstrates how violence influences tourism development deals with elements such as: politics, culture and identity.

The relationship between tourism and symbolic violence, in particular symbolic features of the contemporary cultural landscapes of Bosnia and Herzegovina and Israel/Palestine are presented in Chapter 7. Both cases have to do with identity, identity formation and identity boundaries. Following the case of Palestine, in Chapter 8, Rami Isaac uses the violence and political instability that has existed for almost 65 years to examine the processes that the destination used to reinvent itself.

Chapter 9 presents the case of Caraguatatuba (North of Brazil). The authors argue that violence manifested in crimes have a profound impact on the perception of both, residents and tourists. Their work suggests new research lines concerning the relationships between crime, violence and tourism, and their impacts in social and environmental changes in Brazil.

Chapter 10 provides a qualitative approach to the analysis of the determinants and impacts of terrorism on tourism demand. This is relevant since in academic literature, most of the studies focus on the impacts from a quantitative point of view. Although, as mentioned by Wolfgang Aschauer (the author), the study has its limits, certainly it can be seen as a starting point to follow new approaches in the research of tourism demand.

In Chapter 11, violent incidents involving backpackers and the response of the government are analysed. The authors present evidence about alcohol related violence in the city of Cairns in Australia. Human and organ trafficking are addressed in Chapter 12 by Nancy Scheper-Hughes; she describes cases in different parts of the world, and presents them as problems that are not limited by class or geographic space.

In Chapter 13, Catherine Palmer provides a summary of the main ideas presented throughout the book. It raises questions for reflection and suggests future research directions in the relationship between tourism and violence.

In summary, this book is accessible to the community of tourism scholars and may be of interest to those who want to understand the degree to which violence and tourism are interrelated. 